\title{
Research
}

\section{Developing a complex intervention to reduce time to presentation with symptoms of lung cancer}

\begin{abstract}
Background

Lung cancer is the commonest cause of cancer in Scotland and is usually advanced at diagnosis. Median time between symptom onset and consultation is 14 weeks, so an intervention to prompt earlier presentation could support earlier diagnosis and enable curative treatment in more cases.
\end{abstract}

Aim

To develop and optimise an intervention to reduce the time between onset and first consultation with symptoms that might indicate lung cancer.

\section{Design and setting}

Iterative development of complex

healthcare intervention according to the

MRC Framework conducted in Northeast Scotland.

\section{Method}

The study produced a complex intervention to promote early presentation of lung cancer symptoms. An expert multidisciplinary group developed the first draft of the intervention based on theory and existing evidence. This was refined following focus groups with health professionals and high-risk patients.

\section{Results}

First draft intervention components included information communicated persuasively. demonstrations of early consultation and its benefits, behaviour change techniques, and involvement of spouses/partners. Focus groups identified patient engagement, achieving behavioural change, and conflict at the patient-general practice interface as challenges and measures were incorporated to tackle these. Final intervention delivery included a detailed self-help manual and extended consultation with a trained research nurse at which specific action plans were devised.

\section{Conclusion}

The study has developed an intervention that appeals to patients and health professionals and has theoretical potential for benefit. Now it requires evaluation.

\section{Keywords}

early diagnosis; health services research; lung cancer; primary health care.

\section{INTRODUCTION}

Lung cancer is the most common cancer in the world and Scottish males and females have among the highest rates in the world. ${ }^{1,2}$ In Scotland lung cancer is the commonest cause of cancer and of cancer death in males and females, and disproportionately affects deprived communities. ${ }^{3}$ In the UK, lung cancer has one of the lowest survival outcomes of any cancer, with only around $27 \%$ of males and $30 \%$ of females alive at one year, falling to $7 \%$ and $9 \%$ at 5 years. These figures compare poorly with those of other developed countries, where 5-year survival varies between 11 and 17\%,5,6 Lung cancer survival is linked to the stage at diagnosis with much poorer survival for those with more advanced disease. ${ }^{7,8}$ On the other hand, for early (stage I) disease, treated with surgical resection, 5-year survival rates of up to $90 \%$ have been reported.?

In a recent study it was found that nearly all 360 participants newly diagnosed with lung cancer had experienced symptoms prior to diagnosis, and that the median time between onset of symptoms and consultation was 99 days (interquartile range [IQR] 31-381). ${ }^{10}$ Current UK guidelines recommend referral for investigation after 3 weeks of symptoms, so this study suggests there is potential for more than $75 \%$ of patients to be referred earlier if they consulted earlier. ${ }^{11-13}$ While this 'perfect' consulting behaviour may not be achievable, an intervention aiming to reduce the time taken to consult with chest symptoms would appear to be desirable, timely, and consistent with current health policy initiatives in the UK. ${ }^{14}$ This article describes the development and optimisation of an intervention to reduce the time between onset and first consultation with symptoms that might indicate lung cancer.

\section{METHOD}

\section{Developing the intervention}

The MRC framework was used for the development of interventions to improve health..$^{15}$ In Phase 1, the problem was first defined with reference to the empirical evidence and underlying theory. Second, it was clarified how empirical evidence and underlying theory improves understanding of how the problem is sustained, and which mechanisms could overcome the problem. In Phase 2, first, it was explored in a
S Smith, BSc (Hons), MSc, research assistant P Murchie MSc, PhD, MRCGP senior lecturer:

AJ Lee, MSc, PhD, professor of medical statistics; LD Ritchie, MD, FFPHM, FRCP (Ed), FRCGP,

Mackenzie professor of general practice; NC Campbell, PhD, MA, MD, FRCP, FRCGP, reader, Centre of Academic Primary Care, University of Aberdeen, Aberdeen Health Centre, Aberdeen. G Devereux, PhD, MD, FRCP consultant respiratory physician; MC Nicolson MD, FRCP, consultant medical oncologist, Aberdeen Royal Infirmary, Aberdeen. M Johnston PhD, CPsychol, FRSE, professor in health psychology, Aberdeen Health Psychology Group, University of Aberdeen, Aberdeen. U Macleod, PhD, FRCGP, FHEA, professor of primary care medicine, Hull York Medical School, University of Hull, Hull. R Powell, MSc, PhD, CPsychol, RCUK academic research fellow, Psychology, School of Life and Health Sciences, Aston University, Aston
Triangle, Birmingham. S Wyke, PhD, FRCGP (Hon), interdisciplinary professor of health and wellbeing, Institute of Health and Wellbeing. College of Social Science, University of Glasgow, Glasgow.

\section{Address for correspondence}

Peter Murchie, National School of Primary Care, Centre of Academic Primary Care, University of Aberdeen, Polwarth Building, Foresterhill, Aberdeen, AB25 2ZD.

E-mail: p.murchieđaabdn.ac.uk Submitted: 13 March 2012; Editor's response: 3 April 2012; final acceptance: 18 April 2012. @British Journal of General Practice

This is the full-length article (published online 28 Aug 2011) of an abridged version published in print. Cite this article as: $\mathbf{B r} \mathbf{J}$ Gen Pract 2012; DOI: 10.3399/bjgp12X654579 


\section{How this fits in}

Lung cancer is the commonest cause of cancer death in Scotland and is usually diagnosed at an advanced stage when cure is not possible. Previous research indicates that most people with lung cancer have experienced symptoms and many wait for a long time before consulting their GP. It seems plausible that encouraging people at high risk of lung cancer to consult earlier with potential lung cancer symptoms will result in more people diagnosed early at a potentially curative stage. This study has developed and refined a theory-based intervention incorporating behaviour change techniques which has the potential to prompt earlier consultation in symptomatic patients at high risk of lung cancer.

qualitative study how the mechanisms to overcome the problem were viewed by lung cancer patients, high-risk patients, and GPs. Second, these qualitative data were used to optimise the final intervention that proceeded to an exploratory randomised trial, which has yet to be reported. These processes equate to the development, feasibility and piloting, and evaluation stages of the updated MRC framework. ${ }^{16}$

\section{RESULTS}

Phase 1: Defining the problem, collecting evidence, and developing underlying theory

Phase 1 progressed through five sequential steps led by an expert multidisciplinary group comprising two psychologists, a sociologist, three GPs, a respiratory physician, and a health services researcher. The group had two formal meetings and also worked iteratively on the draft intervention via smaller meetings between members and e-mail contact. The group's work is summarised in Table 1. In Step 1, the group defined and quantified the essential underlying problem as patient behaviour leading to the late presentation of lung cancer symptoms. In Step 2, they identified the target group most likely to benefit from an intervention as people aged $\geq 55$ years, with a history of 20 pack years or more, who are current smokers or gave up within the past 10 years. In Step 3, the key concepts underlying the causative and sustaining pathways of a delayed lung cancer diagnosis were elucidated. The most informative behavioural and social models from health psychology Ifor example, the Illness Action Model, Theory of Planned Behaviour, Zola's triggers: see Table 2) to address each concept were identified. These were then used to develop the construct encapsulating the way in which the concept caused or sustained late diagnosis. This was further mapped on to evidence that supported the theory (Table 2). In Step 4, theory and evidence were mapped on to concrete behaviour change techniques (such as goal setting, action planning, and prompts/cues: see Table 3) to positively impact on the causative and sustaining pathways (Table 3). In Step 5, the potential benefit of the intervention was quantified (Table 1).

Also accomplished within Step 5 was the synthesis of identified techniques into the first draft of the intervention (Figure 1). In summary, it comprised a nurse consultation (which included physical examination and spirometryl in which the patient was introduced to a home-based self-help manual providing information and behaviour change techniques, and was guided in making 'if-then' action and coping plans. The consultation and self-help manual sought to increase the salience and personal relevance of chest symptoms, introduce chest disease prototypes, reinforce the benefits of early intervention in lung cancer and other chest disease, sanction early consultation, tackle barriers to consultation, and develop good personalised action and coping plans.

\section{Phase 2: Optimising the intervention prior} to implementation

To optimise the intervention the study explored its implementation in focus groups with GPs, high-risk patients, and patients with lung cancer. People at high risk of lung cancer lsmokers and ex-smokers with and without lung disease, non-smokers with lung diseasel and partners of smokers were recruited through two general practices in Northeast Scotland and the Aberdeen British Lung Foundation's Breath Easy Group. Patients with lung cancer were recruited with assistance from the specialist lung cancer nurses at Aberdeen Royal Infirmary. GPs were approached through the Grampian teaching practices group.

Two focus groups were conducted, one for high-risk patients at a community location (with seven participants), and one for GPs at a health centre in Aberdeen (four participants). Six individual interviews were conducted with patients with lung cancer, mostly in their own homes. In two cases, spouses/partners stayed for the interview.

During focus groups, practice meetings, and interviews, participants were presented with a summary of the intervention. The study explored positive and negative 


\section{Table 1. Developing an intervention: defining and understanding the problem}

1. Define and quantify the problem
Key Tasks

\section{Commentary}

Lung cancer is usually advanced and incurable at diagnosis. If more patients had earlier stage disease at diagnosis, more could be treated curatively and survival times from palliative treatment could be lengthened. A systematic review of factors that increase patient delay in lung cancer found non-recognition of symptom seriousness, older age, and lower education and social class were associated with later presentation, which is the essential underlying problem. A previous study found that the median time between onset of symptoms and consultation was 99 days (14 weeks) (IQR 31-381).

2. Identify and quantify the population most affected, most at risk, or most likely to benefit from the intervention

3. Understand the pathways by which the problem is caused and sustained

The most important risk factors for lung cancer are pack years of smoking and increasing age. Trials of lung cancer screening have generally defined 'low risk' as a history of less than 20 pack years and 'high risk' as a history of 20 pack years or more. Among ex-smokers, increased risk persists after smoking cessation for at least 10 years. Between 1999 and 2003 in Scotland, 92\% of males and females diagnosed with lung cancer were aged $\geq 55$ years. Therefore, a Scottish population aged $\geq 55$ years, with a history of 20 pack years or more, who are current smokers or gave up within the past 10 years, can be regarded as at high risk of developing lung cancer and as an appropriate target group for this intervention. It is estimate that approximately $5 \%$ of the population of Northeast Scotland fall into this high risk group.

In another study by the same authors independently predictive factors of delayed presentation were:

- Symptoms - those whose first symptoms were cough, shortness of breath, change in longstanding cough, haemoptysis, or loss of appetite, consulted sooner than those without. Those with a change in a longstanding cough waited longer than the median total delay.

- Past medical history - those with COPD waited longer, but those with renal failure or a previous chest infection went sooner. Those with known cardiovascular disease went sooner, but those with previous gastrointestinal disease waited longer.

- Social - increasing time between first symptom and consultation was associated with living alone. There was a non-significant trend for those without paid work to take longer ( $P=0.09$ ).

- Behavioural - Increasing pack years of smoking was associated with longer delay

- Health service factors - frequent consulters consulted sooner. There was a non-significant trend for those who knew their GP well socially to take longer ( $P=0.08)$.

- Knowledge - those reporting more knowledge of lung cancer took longer to consult.

Several psychological and social models can be used to conceptualise the pathways that lead from symptom onset to consultation in lung cancer. These include the Zola's Triggers; Social Cognitive Theory; Common Sense Self-Regulation Model; Illness Prototypes; Illness Action Model; Network Episode Model. Consequently the finding is interpreted in light of these. These models are about observation rather than action so the study moved towards the Theory of Planned Behaviour and Implementation Intentions. This helped the study to clarify the pathways by which the problem was caused and sustained, and hence the targets for action.

Symptom appraisal: could be impacted by raising salience of lung cancer as a possible cause for symptoms Attitudes to consultation: could be enhanced by emphasising the potential benefits of early consultation and the acceptability of doing so

Subjective norm: involving others in the intervention, for example spouses, friends, may heighten subjective norm (social pressure to perform an action), influencing intention to act. Involving others may also influence symptom appraisal and attitudes to consultation.

Perceived behavioural control or self-efficacy: could be impacted by establishing that getting an appointment in primary care is 'easy' partly by training in phrases to use to get a consultation.

Implementation intentions: could be enhanced by clear action plans supported by the knowledge that their own practice was participating in and supportive of the study and consultation was sanctioned. Additionally, reception staff were asked to provide access to these patients reporting appropriate symptoms.

5. Quantify the potential for improvement
The study's previous research suggests that $75 \%$ of people with lung cancer have the potential to consult sooner. They thus estimate that the intervention has the potential to cause this proportion of people with lung cancer to initially consult sooner responses, perceived consequences, methods of implementation, barriers and facilitators to implementation, methods to optimise attendance, and possible solutions to negative consequences and barriers. Focus groups and interviews were audiotaped and transcribed. Notes were taken during practice meetings. Data were analysed inductively, to identify unanticipated themes, and deductively, to identify problems with and barriers to the intervention as well as possible solutions.

General comments were positive, such as 'Excellent idea, it's got to be done, but a tall task' (lung cancer patient). Most comments about problems for the intervention could be grouped into three main themes: engaging patients; achieving behavioural change; and the patient-general practice interface. 


\section{Table 2. Theories and evidence on how late consultation is caused and sustained}

\section{Key concept 1: reaction to symptoms}

\begin{tabular}{|c|c|c|c|}
\hline Elements & Theoretical model & Relevant construct & Related evidence in chest disease \\
\hline \multirow[t]{2}{*}{ Knowledge } & Illness Prototypes ${ }^{25}$ & $\begin{array}{l}\text { Ideas of what symptom-sets are associated with } \\
\text { particular conditions } 25,26\end{array}$ & $\begin{array}{l}\text { Less delay if previous experience of serious } \\
\text { acute chest disease but longer delay if } \\
\text { previous experience of chronic chest disease } \\
\text { and self-reported greater knowledge of lung } \\
\text { cancer symptoms }{ }^{10}\end{array}$ \\
\hline & Illness Action Model ${ }^{27}$ & $\begin{array}{l}\text { 'Stock of knowledge'- built up through personal } \\
\text { experience, interacting with others and general } \\
\text { media }{ }^{27}\end{array}$ & \\
\hline \multirow[t]{2}{*}{ Appraisal } & Illness Action Model ${ }^{27}$ & $\begin{array}{l}\text { Cognitive appraisal or interpretation based on } \\
\text { what is known about symptoms }{ }^{27}\end{array}$ & $\begin{array}{l}\text { Systematic review found non-recognition of } \\
\text { symptom seriousness was associated with } \\
\text { delay. }{ }^{32,33} \text { Most symptoms are not } \\
\text { appraised as serious even in retrospect. }{ }^{10} \\
\text { Qualitative evidence that fear could deter } \\
\text { consultation }{ }^{34}\end{array}$ \\
\hline & $\begin{array}{l}\text { Common Sense } \\
\text { Self-Regulation Model }{ }^{24}\end{array}$ & $\begin{array}{l}\text { Identity, cause, timeline consequences, control/ } \\
\text { curability, emotional response to symptoms }{ }^{24}\end{array}$ & \\
\hline \multirow[t]{2}{*}{ Salience } & Illness Action Model ${ }^{27}$ & $\begin{array}{l}\text { Symptoms can be in the background, not } \\
\text { foreground, of thinking depending on what else } \\
\text { is happening in patient's life unless they are } \\
\text { force higher in 'system of relevance' }\end{array}$ & $\begin{array}{l}\text { Less delay with some symptoms (usually } \\
\text { more dramatic) than others (usually vague) } \\
\text { Longer delay if live alone }^{10}\end{array}$ \\
\hline & Zola's Triggers 22 & $\begin{array}{l}\text { Salience can be affected by interpersonal crises } \\
\text { and interference with relationships and work }\end{array}$ & \\
\hline
\end{tabular}

\section{Key concept 2: approaches to coping with/action on symptoms}

\begin{tabular}{ll}
$\begin{array}{l}\text { Common Sense } \\
\text { Self-Regulation Model }{ }^{24}\end{array}$ & $\begin{array}{l}\text { Continuous process of performing coping } \\
\text { Illness Action Model }{ }^{27}\end{array}$ \\
& $\begin{array}{l}\text { strategies/actions (for example 'waiting to see', } \\
\text { appraisal, and then re-appraising the } \\
\text { health threat }\end{array}$ \\
\hline Zola's Triggers 22 & $\begin{array}{l}\text { Temporalisation - waiting to see what happened } \\
\text { with symptoms before consulting }\end{array}$
\end{tabular}

Qualitative evidence that symptoms

appraised as minor were attributed to benign causes, managed by 'waiting to see' and self-treatment or put to the back of patients' minds until they could no longer do so ${ }^{10,33}$ with symptoms before consulting

\section{Key concept 3: attitude to consulting}

Personal opinion Theory of Planned Attitude to consulting at an early stage formed Behaviour $29,30 \quad$ in response to beliefs about the consequences of consulting

Less delay if symptoms appraised as being serious. ${ }^{35}$

Qualitative evidence of smokers feeling discouraged from consulting because of doctors preoccupied with anti-smoking ${ }^{10,33}$

\begin{tabular}{|c|c|c|c|}
\hline \multirow[t]{3}{*}{ Opinions of others } & Zola's Triggers ${ }^{22}$ & $\begin{array}{l}\text { Interactions with others can lead to sanctioning } \\
\text { of consultation or to advice for further } \\
\text { 'wait and see. }\end{array}$ & Longer delay if live alone $e^{10}$ \\
\hline & $\begin{array}{l}\text { Theory of Planned } \\
\text { Behaviour } 29,30\end{array}$ & $\begin{array}{l}\text { Subjective norm: social pressure to consult at } \\
\text { an early stage }\end{array}$ & \\
\hline & Network Episode Model ${ }^{28}$ & $\begin{array}{l}\text { Responses shaped by interacting with others, } \\
\text { resource sharing, suggestion, support, and nagging }\end{array}$ & \\
\hline Forming intentions & $\begin{array}{l}\text { Theory of Planned } \\
\text { Behaviour } 29,30\end{array}$ & $\begin{array}{l}\text { Intentions to consult at an early stage formed in } \\
\text { response to attitudes, subjective norms, and } \\
\text { perceived behavioural control }\end{array}$ & \\
\hline \multicolumn{4}{|c|}{ Key concept 4: carrying through to action } \\
\hline \multirow[t]{2}{*}{ Self-efficacy } & Social Cognitive Theory ${ }^{23}$ & $\begin{array}{l}\text { Self-efficacy - confidence that one can make } \\
\text { an appointment. This can be based on previous } \\
\text { experience }\end{array}$ & Less delay from frequent consulters ${ }^{10}$ \\
\hline & $\begin{array}{l}\text { Theory of Planned } \\
\text { Behaviour }\end{array}$ & $\begin{array}{l}\text { Perceived behavioural control - extent to which } \\
\text { patient feels he or she has control over the } \\
\text { behaviour (making an appointment) }\end{array}$ & \\
\hline $\begin{array}{l}\text { Intention-behaviour } \\
\text { gap }\end{array}$ & Implementation Intentions ${ }^{31}$ & $\begin{array}{l}\text { Implementation intentions: forming precise } \\
\text { intentions to enact a particular behaviour (for } \\
\text { example making appointment with doctor) when } \\
\text { a particular situation occurs }\end{array}$ & $\begin{array}{l}\text { Qualitative evidence of patients saying they } \\
\text { don't want to waste doctor's time } e^{10,33}\end{array}$ \\
\hline
\end{tabular}




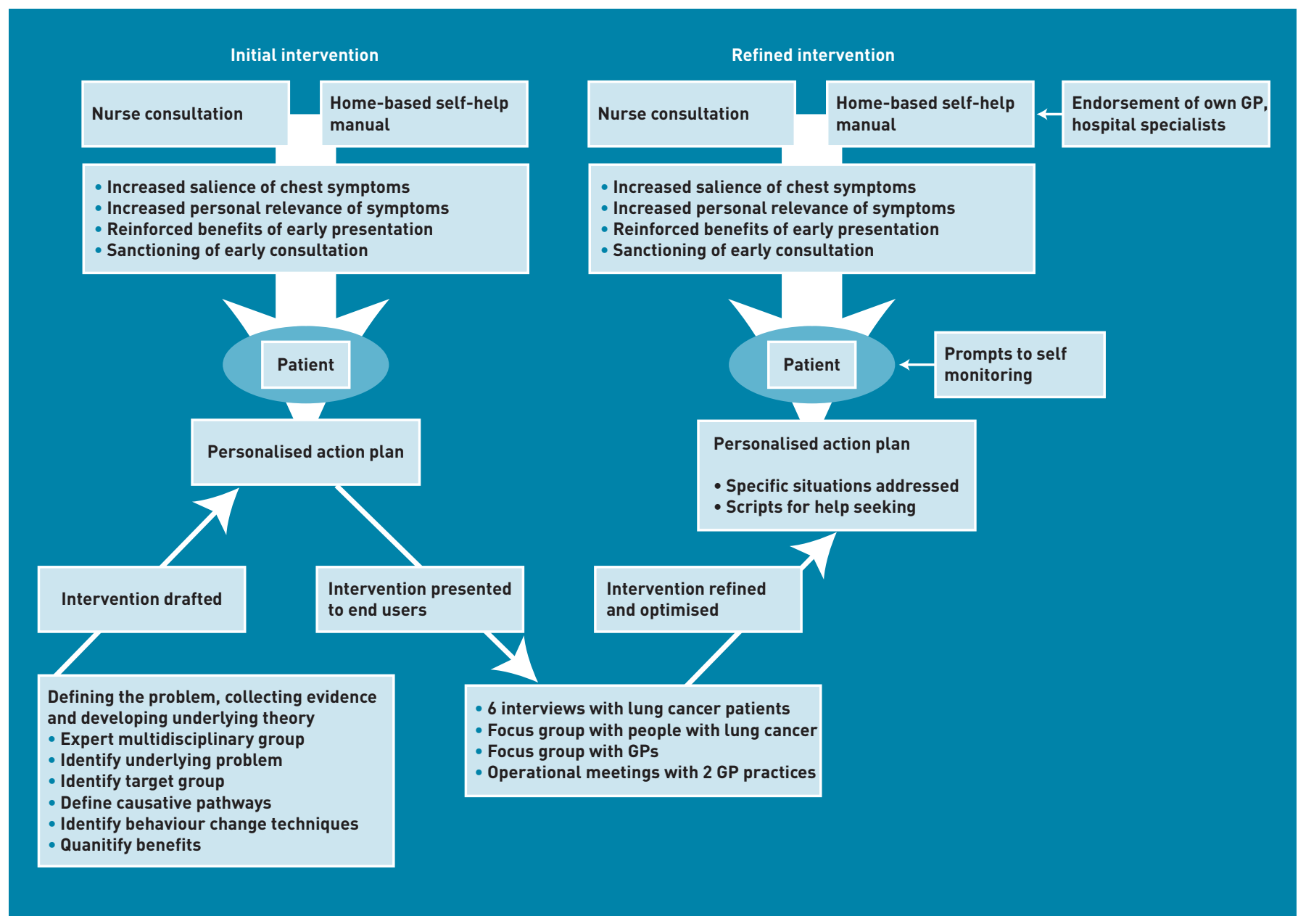

Figure 1. Progress of intervention development.

\section{Engaging patients - 'the hook'}

There were concerns from all three groups that recruitment to the intervention would be difficult and non-attendance rates high. Smokers were thought by the high-risk group to be in denial', believing 'it's not going to affect me [the smokers]'. 'They don't apply it [knowledge of the risks of smoking] to themselves.' 'I really think it's the apathy of some people - they don't want to know. 'One said:

Before I stopped smoking, it [the intervention self-help manual] would go in the bin.' (high-risk group)

There were similar comments from the interviewees with lung cancer:

'Some people just don't care about their health' and 'might not want to know.

The GPs commented that many in this group 'don't listen to advice'.

The need for a 'hook' was emphasised repeatedly:
'The key thing's to get people hooked.

Unless it is something really interesting you just stick it to the side.

'Something that jumps out of the envelope and punches you on the nose!'

'What's in it for me?'

An approach based on striking slogans was thought good:

'Sell, sell, sell - "nip lung disease in the bud"', the hard sell has got to be there, [with] impact on the front page.' (high-risk group).

The nature of the hook was more difficult, but several ideas were generated. The $1,2,3$ ' slogan in the draft intervention selfhelp manual was applauded:

1,2,3 page should be at the front - it pulled me in right away - and it should also be repeated at the back'. (lung cancer patient)

Celebrity endorsement was suggested by 


\begin{tabular}{|c|c|c|}
\hline Label & Definition & Example \\
\hline Health consequences & $\begin{array}{l}\text { Record/provide information about health } \\
\text { consequences of behaviour }\end{array}$ & $\begin{array}{l}\text { 'It's worth having symptoms dealt with because } \\
\text { treatments can make you feel better, improve your } \\
\text { quality of life, and even extend your life!' (p13) }\end{array}$ \\
\hline Salience of consequences information & $\begin{array}{l}\text { Make information about the consequences } \\
\text { of changing the behaviour more obvious }\end{array}$ & $\begin{array}{l}\text { Salience is reinforced with a case study of an individual } \\
\text { who initially ignored symptoms but finally did see the } \\
\text { doctor. Lung cancer was diagnosed and treatment } \\
\text { began. (p15) }\end{array}$ \\
\hline Prompts/cues & $\begin{array}{l}\text { Use environmental, social or internal stimuli } \\
\text { to prompt or cue performance of wanted } \\
\text { behaviour or non-performance of unwanted } \\
\text { behaviour }\end{array}$ & $\begin{array}{l}\text { Participants are invited to choose prompts which will } \\
\text { remind them to check for symptoms: either a text } \\
\text { message, postcard or stickers. (p11) } \\
\text { Participants are given a list of prompts (for example, if on } \\
\text { one of my regular checks I have any symptoms ... to which } \\
\text { they suggest appropriate behavioural responses. (p11) }\end{array}$ \\
\hline Social support (general) & $\begin{array}{l}\text { Advise on or facilitate development of general } \\
\text { social support for the behaviour from friends, } \\
\text { relatives, colleagues or 'buddies' }\end{array}$ & $\begin{array}{l}\text { 'Let your family, friends or carers read this handbook; } \\
\text { there may be ways they can help' (p3) }\end{array}$ \\
\hline Action planning & $\begin{array}{l}\text { Prompt detailed planning of the behaviour } \\
\text { goal including context, frequency, intensity } \\
\text { and duration of performance }\end{array}$ & $\begin{array}{l}\text { Participants are asked to plan the behaviours they will } \\
\text { perform in response to prompts such as if on one of my } \\
\text { regular checks I have any symptoms...' (p11) }\end{array}$ \\
\hline Instruction on how to perform a behaviour & $\begin{array}{l}\text { Instruct how to perform a behaviour or } \\
\text { preparatory behaviours }\end{array}$ & 'Phone for an appointment' (p6) \\
\hline Vicarious reinforcement & $\begin{array}{l}\text { Facilitate observation of the consequences } \\
\text { for others when they perform the target } \\
\text { behaviour }\end{array}$ & $\begin{array}{l}\text { 'I wouldn't be here now if it weren't for the medication } \\
\text { that I'm on. (quote from celebrity Liz Dawn, p1) }\end{array}$ \\
\hline $\begin{array}{l}\text { Anticipation of future rewards or removal } \\
\text { of punishment }\end{array}$ & $\begin{array}{l}\text { Inform that future rewards or removal of } \\
\text { future punishment will be contingent on } \\
\text { performance of wanted behaviour }\end{array}$ & $\begin{array}{l}\text { A list of lung diseases are presented with information on } \\
\text { how the illnesses can be treated (to either cure the } \\
\text { disease or relieve symptoms) if diagnosed. (p9) }\end{array}$ \\
\hline Verbal persuasion to boost self-efficacy & $\begin{array}{l}\text { Tell the person that they can successfully } \\
\text { perform the behaviour, arguing against self } \\
\text { doubts and asserting that they can and } \\
\text { will succeed }\end{array}$ & 'It's as easy as $1 \ldots 2 \ldots 3 . .$. '(p6) \\
\hline Goal setting (behaviour) & $\begin{array}{l}\text { Set a goal defined in terms of the behaviour } \\
\text { to be achieved }\end{array}$ & $\begin{array}{l}\text { Participants are presented with the behavioural goal } \\
\text { 'Phone your surgery today to make an appointment' } \\
\text { on experiencing symptoms (p8) }\end{array}$ \\
\hline Persuasive communication & $\begin{array}{l}\text { Present verbal or visual arguments from a } \\
\text { credible source in favour of or against } \\
\text { the behaviour }\end{array}$ & 'It's definitely worth your while' (p3) \\
\hline Modelling of the behaviour & $\begin{array}{l}\text { Provide an example for people to aspire to } \\
\text { or imitate }\end{array}$ & $\begin{array}{l}\text { The target of the case study models the behaviour of } \\
\text { seeking help - 'I said "Och I better go an see about this } \\
\text { cough", so I went tae my local doctor. (p15) }\end{array}$ \\
\hline
\end{tabular}

members of the high-risk group. Targeted patients should be made to feel they were getting special attention, rather than stigmatised as usual:

'It's getting a little bit more attention', 'like a lung screening,' (high-risk group), or being made to feel they were being moved from a 'non-priority up to a priority' (GP group). There were differing views on the role of fear. Its use was advocated as a way to make people take notice initially:

'What would make me want to find out is if it might be cancer - everybody is afraid of cancer I think, and therefore if you get something which will alert you to the fact that you might have cancer then you'd read it - whereas if it was other things you wouldn't worry that much about them.'

'It's a good thing raising anxiety in people that smoke ... terrify the buggers that's what I say!' (high-risk group)

On the other hand, there were concerns that it may also be counter-productive and that people "may be too scared llung cancer group). 'What they are going to be doing is being scared, if they get symptoms 
they will ignore it (high-risk group).

One strategy suggested by GPs was to tie the intervention in with something else (for example COPD reviews). This was based on previous experience of attempting to implement similar interventions opportunistically on hard-to-reach groups.

\section{Achieving behavioural change}

Even once 'captured' for a consultation, there were concerns about whether achieving behaviour change was possible. As above, reasons included non-recognition of personal risk, optimistic bias, and apathy. Much of the discussion of possible solutions also followed the above pattern, with emphasis on the need for a 'hook' and discussion about whether fear would encourage or hinder action. There were also several other specific ideas and suggestions. There was considerable discussion about the need for support and sanctioning:

'Support is important - it's surprising the number of people that have been really worried about something far worse ... they need support to go and get the diagnosis. (high-risk group).

There was encouragement from the highrisk group for participants to bring a family member, partner, or close friend along to be involved in the intervention. This was also advocated by the GP group, with the proviso that the possibility of conflict between the family member or friend and the participant should be looked for and avoided, as this could be counter-productive. Ideas from both patients and GPs were put forward as a means to prompt self-monitoring of symptoms included calendars, text messaging, postcards, and Post-it ${ }^{\circledR}$ notes, but with a need for plans to be tailored to individuals. GPs suggested prompts on cigarette lighters so patients were prompted to think about their symptoms every time you light up'. There were several specific recommendations for the self-help manual from both the high-risk group and lung cancer patients. These included keeping it simple, emphasising symptoms are not "just because you are older', provision of a helpline, a sprinkling of benefit messages throughout, and quotes from people who have been through it. Finally, GPs advocated sending the booklet to non-attenders anyway, backed up by telephone calls if possible.

\section{Barriers at the patient-general practice} interface

Participants from all groups mentioned potential problems at the patient-general practice interface and made clear that they felt this was a very important part of the explanation for late presentation. The highrisk group was worried that GPs had a negative attitude towards smokers and one said 'I just think GPs don't really know [about lung disease].' There was a need for confidence that GPs would take them seriously. 'Smokers are beginning to think now wait a minute, are they going to treat me because I am a smoker? Patients with lung cancer spoke of the difficulty people can have making appointments: 'Those who live alone or those who are short of cash ... may need help to make appointments ... to go to the appointments. GPs were concerned that the advice in the booklet should be consistent with what was achievable and not foster expectations that could not be met in practice.

The key solution, agreed by all, was for involvement of the entire general practice team in the process:

If recruiting through GP practices, you have got to involve the whole care team receptionists, doctors, nurses. ' (patient with lung cancer).

Receptionists were the first point of contact for patients, so need to be involved. Triage by practice nurses could bring in delay, so they should be involved too. Indeed, this concept was extended to secondary care too:

Everybody has got to be involved: the GPS, the consultants, the hospitals themselves. (patient with lung cancer).

The involvement of GPs should be demonstrable as part of the intervention:

'GP endorsement essential ... make it as personal as possible.' (high-risk group)

Patients with lung cancer felt that advice should be provided on making appointments and exactly what to ask when contacting their general practice. Care was needed to ensure that this wording was in line with what could be implemented in the trial practices. Similarly, but more generally, the wording of recommendations in the booklet should avoid friction between patients and GPs.

Intervention refinement as a result of the focus groups, interviews, and practice meetings

With reference to evidence around the 
diagnosis of lung cancer, underpinning psychological models, and recent recommendations on mapping behavioural determinants to behavioural change techniques, the study used the data from the focus groups to refine that intervention. ${ }^{36}$ Changes included:

\section{- Simplifying checklists.}

- Using the identified barriers to generate action and coping plans.

- Including messages to sanction and encourage appropriate consultation.

- Demonstrating approval of GPs, respiratory physicians, and oncologists for the process.

- Incorporating a celebrity endorsement.

- Providing action plans and prompts (Post-its, postcards, or text messages) for self-monitoring.

- Giving specific advice on what to say when making appointments.

Finally, in two meetings with general practices that had agreed to pilot the intervention, meetings were held with representatives of all staff. These were used to identify potential barriers at the patient-general practice interface and to ensure that the intervention was practically deliverable within these practices. Efforts were also made to minimise the work and disruption for general practices. This required some very minor refinements to account for differences in practice administration systems. None of these changed the final intervention in any material way.

\section{Final intervention}

The intervention comprised a self-help manual, nurse consultation, and system of prompts. The key components of the final intervention are:

- Referring to a range of lung disease, not only cancer.

- Proposing 'special attention' rather than fear message.

- Endorsement by Liz Dawn, best known for her role as Vera Duckworth in Coronation Street, who has emphysema. Messages to sanction and encourage consultation with chest symptoms from Liz Dawn, local specialists in respiratory medicine and oncology, participants' GPs, and others with chest disease.

- Stories and speech bubble messages from patients about early and late consultation.

- Frequent messages about the benefits of early consultation.

- A simple checklist of symptoms that need action and when.

- Prompts to self-monitoring - monthly postcards, texts, or stickers - to themselves and close others.

- If-then action and coping plans based on identified barriers to consultation.

- Specific advice on what to say and expect when making appointments.

- 1,2,3 action plan logo repeated throughout the manual.

The nurse consultation was based on a script produced primarily by the lead health psychologist, the lead research nurse, and the health services researcher for the project. The basis for the script was the intervention self-help manual. The research nurses were advised on what to say as they talked through the manual with the patient. Research nurse training took place over 2 separate days and included nurses simulating consultations with a member of the multidisciplinary team.

The manual was coded independently using a taxonomy of 84 behaviour change techniques to identify the precise techniques used in the intervention. ${ }^{37}$ Where there were disagreements about the presence of a technique, discussion followed until agreement was reached. The twelve techniques included in the manual are given in Table 3, with examples, including prompts/cues, action planning, and goal setting.

\section{DISCUSSION}

\section{Summary}

This study describes the development of an intervention that is feasible and acceptable to potential recipients, and worthy of further evaluation. The experience gathered in this intervention developmental process has clear implications for others seeking to develop similar interventions.

First, considerable care and thought should be expended in the formation of any multidisciplinary group tasked with devising an intervention such as this. The apparent success of the study's developmental process, it is believed, was based in large part on the sound theoretical underpinning of the intervention elements, which, at the same time, was tempered with the practical experience and insights of clinicians used to working with these patient groups. Second, the theoretical 


\section{Funding}

The study was funded by a project grant from Cancer Research UK. CRUK Grant Reference Number C542/A8695.

\section{Ethical approval}

Full ethical approval for the study was granted by the North of Scotland Research Ethics Committee (REC reference number: 08/S0801/13) on February 152008.

\section{Provenance}

Freely submitted; externally peer reviewed.

\section{Competing interests}

All authors have completed the Unified Competing Interest form at www.icmje. org/coi_disclosure.pdf lavailable on request from the corresponding author) and declare that: 1) none of the authors has support from any commercial company for the submitted work; 2) SS, PM, GD, MJ, AL, UM, MN, RP, SW, and NC have no relationships with any commercial company that might have an interest in the submitted work in the previous 3 years; 3) their spouses, partners, or children have no financial relationships that may be relevant to the submitted work; and 4) SS, PM, GD, MJ, AL, UM, MN, RP, SW, LR and NC have no nonfinancial interests that may be relevant to the submitted work.

\section{Acknowledgements}

Grateful thanks to the interested patients and GPs who took part in the interviews and focus groups. Thanks also to Michael Head, Chairperson of the British Lung Foundation's Breath Easy Group, who helped recruit patients for intervention development. Grateful thanks also to the staff at the general practices involved in the study, particularly Dr Peter Watson and Dr lain Small, who provided practical advice on the intervention as it developed.

\section{Discuss this article}

Contribute and read comments about this article on the Discussion Forum: http://www.rcgp.org.uk/bjgp-discuss development of the intervention was iterative, with much discussion, questioning, and refinement of individual components before they developed a concrete form. This ensured shared understanding amongst the multidisciplinary group, which was an essential prerequisite for further refinement once the perspectives of end-users were available. Third, once the intervention had been devised, rather than proceeding directly to a pilot exercise that would have required considerable resources, the study explored the theoretical intervention in focus groups with GPs, high-risk patients, and patients with lung cancer, essentially the end-users of the intervention. As a result, the study was able to effect several refinements that are believed to be likely to improve the intervention. The authors suggest that such exploratory piloting may be a more efficient and cost-effective approach than moving straight to a potentially costly practical pilot exercise. Furthermore, the authors believe that this approach provides a template for others wishing to develop complex healthcare interventions.

\section{Strengths and limitations}

This study describes the development of an intervention underpinned by evidence, theory, and context, and with care taken over wording, presentation, and delivery. Although apparently comprising separate phases, the process was iterative. There was much refining and revising of ideas before the first draft of the intervention emerged, and once the data from focus groups and interviews had been analysed, the expert group was again able to contribute to the fine tuning of the intervention. An iterative process in intervention development has been used and recommended previously by the researchers. ${ }^{38}$ Full engagement of a multidisciplinary team with both theoretical and clinical expertise helped to ensure the intervention was grounded both theoretically and in its context of delivery. Formal consultations (qualitative research) with patients and professionals allowed many of the potential strengths and weaknesses of the intervention to be identified, confirmed, and addressed before it was rolled out to patients. Preparatory work with general practices ensured that the potential barriers faced by patients in securing a GP appointment were taken into account. Care was taken to ensure the intervention was attractive and wording was both easy to read and consistent with underlying theory and evidence. Training in delivery with a clear plan for the way the work of the intervention is actually done by the nurses in the consultations, developed with involvement of the nurses themselves, and supported by a training programme. This should help to ensure fidelity in delivery. ${ }^{39}$ Finally, the specification of the active behaviour change techniques and of the mode of delivery makes it more likely that the intervention is replicable by different investigators as per the WIDER Recommendations to Improve Reporting of the Content of Behaviour Change Interventions. ${ }^{40}$ A further strength worth highlighting is that the detailed development methods presented here could form a template or structure for others developing complex interventions. The processes engaged in that added strength to the intervention are summarised in Box 1.

The study had some limitations. The involvement of patients was only as participants in the qualitative research, not as members of the expert group, and the involvement of secondary care practitioners was only as members of the expert group,

\section{Box 1. Summary of processes engaged in to develop the intervention}

- Full engagement of multidisciplinary team with both theoretical expertise and clinical expertise in general practice, secondary care of chest problems, and behaviour change.

- An iterative process where each stage built on previous stages.

- Use of evidence about patterns of consultation and delay in lung cancer.

- A theoretical basis that drew on a range of disciplines including primary care, sociology, and health psychology.

- Use of well-specified active ingredients of behaviour change (behaviour change techniques).

- Consultation with patients.

- Consultation with health professionals.

- Gaining celebrity endorsement.

- Developing a workbook with good readability and attractiveness.

- Preparatory work with the general practices involved.

- Development of a clear plan for the work done by the nurses in the consultations with patients.

- Training of the nurses conducting the consultations.

- Replicable intervention based on specified behaviour change techniques, mode of delivery, self-help manual, and training script for the person delivering the intervention. 
not as participants in the qualitative research. It is possible that including patients in the expert group may have had benefits, such as helping with the language of the intervention, while interviewing more secondary care practitioners may have revealed more issues for them, such as effects on secondary care workload. The study elected not to select a single psychological theory to underpin their intervention, but rather took elements from several theories (as described in Table 2) that best fitted the empirical evidence. While this approach may be criticised as not being theoretically pure, it draws from recent research grouping constructs from different theories into 'construct domains' and identifying behavioural change techniques for each domain. ${ }^{36,42}$

\section{Implications for practice and research}

This intervention has been carefully designed to accord with the ideas, concerns, and expectations of patients and health professionals in Northeast Scotland. It has a mechanism of action that has the theoretical potential for benefit. Now it requires evaluation. 


\section{REFERENCES}

1. Ferlay J, Shin HR, Bray F, et al. Estimates of worldwide burden of cancer in 2008: GLOBOCAN 2008. Int J Cancer 2010; 127(12): 2893-2917.

2. Cancer Research UK. Lung cancer: UK incidence statistics. http://info cancerresearchuk.org/cancerstats/types/lung/incidence/ laccessed 30 Jul 2012).

3. ISD Online, Information and Statistics Division, NHS Scotland. Cancer statistics: lung cancer and mesothelioma. http://isdscotland.org/Health-Topics/Cancer/ Cancer-Statistics/Lung-Cancer-and-Mesothelioma/ laccessed 30 Jul 2012).

4. Cancer Research UK. Lung cancer: survival statistics. http://info. cancerresearchuk.org/cancerstats/types/lung/survival/ laccessed 30 Jul 2012).

5. Ries, LAG, Harkins D, Krapcho M, et al (eds.). SEER cancer statistics review, 1975-2003. Bethesda, MD: National Cancer Institute, 2006.

6. Berrino F, De Angelis R, Sant M, et al, and the EUROCARE Working Group. Survival for eight major cancers and all cancers combined for European adults diagnosed in 1995-99: results of the EUROCARE 4 study. Lancet Oncol 2007; 8(9): 773-783

7. Scottish Executive Health Department. Cancer scenarios: an aid to planning cancer services in Scotland in the next decade. Edinburgh: Scottish Executive, 2001

8. Campbell NC, Elliott AM, Sharp $L$, et al. Rural and urban differences in stage at diagnosis of colorectal and lung cancers. Br J Cancer 2001; 84(7): 910-914.

9. Jensen AR, Mainz J, Overgard J. Impact of delay on diagnosis and treatment of primary lung cancer. Acta Ontol 2002; 41(2): 147-152.

10. Smith SM, Campbell NC, MacLeod U, et al. Factors contributing to the time taken to consult with symptoms of lung cancer: a cross-sectional study. Thorax 2009; 64(6): 523-531.

11. National Institute for Health and Clinical Excellence. The diagnosis and treatment of lung cancer. London: National Collaborating Centre for Acute Care, 2005

12. Scottish Intercollegiate Guidelines Network. Management of lung cancer. Edinburgh: SIGN, 2005

13. UK Lung Cancer Coalition. Lung cancer plan: improving lung cancer survival in the UK. London: UKLCC, 2007.

14. Richards MA. The size of the prize for earlier diagnosis of cancer in England. $\mathrm{Br}$ J Cancer 2009; 101(Suppl 2): S125-129.

15. Campbell NC, Murray E, Darbyshire J, et al. Designing and evaluating complex interventions to improve health care. BMJ 2007; 334(7591): 455-459.

16. Craig $P$, Dieppe $P$, Macintyre $S$, et al. Developing and evaluating complex interventions: the new Medical Research Council guidance. BMJ 2008; 337: a1655.

17. Macleod U, Mitchell E, Burgess C, et al. Risk factors for delayed presentation and referral of symptomatic cancer: evidence for common cancers. Br J Cancer 2009; 101(Suppl 2): S92-101.

18. International Agency for Research on Cancer. Tobacco smoke and involuntary smoking. IARC Monographs on the Evaluation of Carcinogenic Risks to Humans Volume 83. Lyon: World Health Organization, 2002.

19. Mulshine JL, Sullivan DC. Lung cancer screening. N Engl J Med 2005; 352(26): 2714-2720.

20. US Preventive Services Task Force. Lung cancer screening. 2004. umw.ahrq gov/clinic/uspstf/uspslung.htm (accessed 30 Jul 2012).

21. Lange JH, Mastrangelo G, Fadda E, et al. Elevated lung cancer risk shortly after smoking cessation: is it due to a reduction of endotoxin exposure? Med Hypotheses 2005; 65(3): 534-541.

22. Zola I. Pathways to the doctor: from person to patient. Soc Sci Med 1973; 7(9): 677-689.

23. Bandura A. Self-efficacy: toward a unifying theory of behavioural change. Psychol Rev 1977; 84(2): 191-215.

24. Leventhal H, Meyer D, Nerenz D. The commonsense representations of illness danger. In: Rachman S (ed.). Contributions to medical psychology, vol 2. New York, NY: Pergamon Press, 1980

25. Bishop GD, Converse SA. Illness representations: a prototype approach. Health Psychol 1986; 5(2): 95-114.

26. Andersen BL, Cacioppo JT, Roberts DC. Delay in seeking a cancer diagnosis: delay stages and psychophysiological comparison processes. Br J Soc Psychol 1995; 34(Pt 1): 33-52.

27. Dingwall R. Aspects of illness. 2nd edn. Cardiff papers in qualitative research. Burlington, VT: Ashgate, 2001.

28. Pescosolido B, Levy JA. The role of social networks in health, illness, disease and healing: the accepting present, the forgotten past, and the dangerous potential for a complacent future. Soc Networks Health 2002; 8: 3-25.

29. Ajzen I. From intention to actions: a theory of planned behavior. In: KuhlJ, Beckman J (eds.). Action control: from cognitions to behavior. New York, NY: Springer-Verlag, 1985.

30. Ajzen I. The theory of planned behavior. Organ Behav Hum Dec 1991; 50(1): 79-211.

31. Gollwitzer PM. Implementation intentions: strong effects of simple plans. Am Psychol 1999; 54(7): 493-503.

32. Macdonald S, Macleod U, Mitchell E, et al. Factors influencing patient and primary care delay in the diagnosis of cancer: a database of existing research and its implications for future practice. Final report to the Department of Health (Ref 1217522). Glasgow: University of Glasgow, 2004.

33. Corner J, Hopkinson J, Fitzsimmons D, et al. Is late diagnosis of lung cancer inevitable? Interview study of patients' recollection of symptoms before diagnosis. Thorax 2005; 60(4): 314-319.

34. de Nooijer J, Lechner L, de Vries H. A qualitative study on detecting cancer symptoms and seeking medical help; an application of Andersen's model of total patient delay. Patient Educ Couns 2001; 42(2): 145-157.

35. Macdonald S, Macleod U, Campbell NC, et al. Systematic review of factors influencing patient and practitioner delay in diagnosis of upper gastrointestinal cancer. Br J Cancer 2006; 94(9): 1272-1280.

36. Michie S, Johnston M, Francis J, et al. From theory to intervention: mapping theoretically derived behavioural determinants to behaviour change techniques. Appl Psychol-Int R2008; 57: 660-680.

37. Abraham C, Michie S. A taxonomy of behavior change techniques used in interventions. Health Psychol 2008; 27: 379-387.

38. Murchie P, Hannaford PC, Wyke S, et al. Designing an integrated follow-up programme for people treated for cutaneous malignant melanoma: a practical application of the MRC framework for the design and evaluation of complex interventions to improve health. Fam Pract 2007; 24(3): 283-292

39. Hardeman W, Michie S, Fanshawe T, et al. Fidelity of delivery of a physical activity intervention: predictors and consequences. Psychol Health 2008; 23: $11-24$.

40. Abraham CA, Albarracín D, Araújo-Soares V, et al. WIDER recommendations to improve reporting of the content of behaviour change interventions. 2009. http:// interventiondesign.co.uk/wp-content/uploads/2009/02/wider-recommendations. pdf (accessed 30 Jul 2012).

41. Michie M, Abraham C, Eccles MP, et al. Strengthening evaluation and implementation by specifying components of behaviour change interventions: a study protocol. Implement Sci 2011; 6: 10.

42. Michie S, Johnston M, Abraham C, et al. on behalf of the Psychological Theory Group. Making psychological theory useful for implementing evidence based practice: a consensus approach. Qual Saf Health Care 2005; 4(1): 26-33. 